of fibres could not be observed. From the data given above, however, the following points emerge :

(1) The heavily pigmented fibres (I.) vary considerably in length.

(2) The irregular segmental mosaic pattern of the scales of the heavily pigmented fibres (I.) is also seen in portions of the long coarse white fibres (III.).

(3) There occurs in the sample a fibre (II.) which shows both generalised and irregular segmental mosaic scaling, and in addition is intermediate even so far as pigmentation is concerned, between the fibres under the headings I. and III.

(4) A long white fibre is present, intermediate in general appearance between the fine short wool fibre (V.) and the coarse white fibre (I.), and showing the two mosaic types of scaling.

The approximation, therefore, of the scale pattern and other features of all these classes of fibres, suggests that their separation into three constitutional fibre types is hardly possible on the data available. An accurate conception of the constitution of the coat of this sheep can scarcely be gained until further observations are made over a considerable period on the growth and shedding of its constituent fibres.

Zoology Department, University,

$$
\text { A. B. Wildman. }
$$
Leeds, April 19.

1 NAture, 129, 128, Jan. 23, 1932 ; 129, 436, March 19, 1932.

\section{Senile Degeneration in Plants}

THE question of the 'wearing out' of varieties of cultivated plants that are propagated asexually is a subject of recurring discussion, one of the latest contributions being a paper by Bijhouwer. ${ }^{1}$

The classical example is that afforded by the continual replacement of varieties of potatoes by newer varieties, which in their turn seem to lose vigour and disappear from cultivation. But this may be explicable by the tendency of potato stocks to accumulate 'virus' diseases, which will eventually reduce the cropping power of the variety by one-half. Again, the Ribston Pippin apple is often quoted as a variety that has become so liable to canker that it can only profitably be grown on the most favoured soils. But there is evidence that from the time of its general distribution, about a hundred and fifty years ago, Ribston Pippin has been a bad 'doer', retained on account of the outstanding quality of its fruit. So the argument runs on ; one school maintaining that varieties not regenerated from seed grow old, while the other argues that the evidence points either to the accumulation of disease or to practical displacement by the introduction of improved varieties. The purpose of this note is merely to direct attention to a most remarkable example, which seems to have escaped notice, of age in a clone only propagated vegetatively.

The saffron crocus (Crocus sativus Linn.) has been cultivated on a large scale for a very long time. It is still grown in Spain, Italy, and the Mediterranean countries to yield commercial saffron (the dried stigmas of the flower). It was grown as a crop in the sixteenth and seventeenth centuries between Saffron Walden and Cambridge (vide a paper presented by the Hon. Charles Howard to the Royal Society in 1678). ${ }^{2}$ Yet the saffron crocus of cultivation is a sterile clone, increasing only by the numerous small offset corms it produces. No wild habitat is known, and though there are several closely related forms from Greece and the Levant which are fertile, none is identical with the true saffron crocus. Its sterility is reported by all the old writers and is now explicable by its irregular chromosome constitution. But the exceptional feature is the antiquity of the records we possess of the saffron crocus. Not only was saffron as dye and drug familiar to the Greeks, but also in the Temple of Minos, in Crete, Sir Arthur Evans disclosed a beautiful fresco representing a man gathering saffron, the identity of the flowers being unmistakable because of the highly coloured protruding stigmas. The fresco is reproduced in colours in Sir Arthur Evans's "The Temple of Minos ", vol. 1, p. 265. The fresco belongs to the Middle Minoan period, c. 1900-1800 B.c., thus giving a recorded history for this clone of more than 3700 years.

The John Innes Horticultural Institution, London, S.W.19, May 5.

1 Abbreviated version, J. Pomology, 9, $122 ; 1931$.

2 Phil. Trans., 12, $945 ; 1678$.

Feeding Experiments with Methionine

WE have, for some time, been interested in the metabolism of methionine, for which one of us (T. E. W.) has, with Prof. G. Barger, devised a new synthesis. ${ }^{1}$ An attempt to find the effect of methionine on growth of rats was actually in progress when R. W. Jackson and R. J. Block ${ }^{2}$ announced that methionine, added to a cystine-deficient diet, produced extra growth as compared with controls. As, however, these workers have not yet published figures or experimental details, we consider it worth while reporting our results which confirm their announcement.

The diet we used was that of Sherman and Merrill ${ }^{3}$ (using marmite and cod liver oil as sources of vitamins), of which a sufficient supply was mixed in one batch for the whole experiment. To a quarter of this, $l$-cystine was added ( $2 \mathrm{gm}$. per kilo) and thoroughly mixed in, while to a second quarter $d$-l-methionine $(2.5 \mathrm{gm}$. per kilo) was similarly added, and the remainder kept for control.

During the control period, which all animals underwent, we adjusted the amount of food supplied so that it was all consumed, but was near the limit of the animals' appetite. Thereafter, both during the remainder of the control period, when only weight measurements were being made, and after transference to cystine or methionine containing diets, this amount of food ( $8 \mathrm{gm}$.) was supplied to each rat.

The average increase in weight per rat over a period of 25 days was as follows : controls, $16.0 \mathrm{gm}$. ; cystine, $27.0 \mathrm{gm}$.; methionine, $22.5 \mathrm{gm}$. During the preceding control period of 25 days the three groups increased by $12.5 \mathrm{gm} ., 12.1 \mathrm{gm}$., and $13.6 \mathrm{gm}$. per rat respectively.

It appears that $d-l$-methionine, added to the Sherman-Merrill diet, can produce increased growth in rats, and in this respect it is almost as efficient as cystine. It is curious to find two substances of such different chemical structure acting in the same way, and accordingly we have experiments in progress to determine whether cystine and methionine are interchangeable and utilisable for the same purpose, or whether they are both 'essential' amino acids in which the Sherman-Merrill diet is deficient. We are also comparing the effects of dextro- and lævomethionine. T. E. WEICHSELBAUM.

M. B. Weichselbaum. C. P. Stewart.

Department of Medical Chemistry, University of Edinburgh, April 25.

1 G. Barger and T. E. Weichselbaum, Biochem. J., 25, 997; 1931

${ }_{3}^{2}$ R. W. Jackson and R. J. Block, Science, 74, 414; 1931

No. 3265, VoL. 129] 